\title{
A Study on Performance, Combustion and Emission Characteristics of Compression Ignition Engine Using Fish Oil Biodiesel Blends
}

\author{
D. K. Ramesha $\cdot$ Rajiv K. Thimmannachar • \\ R. Simhasan · Manjunath Nagappa • \\ P. M. Gowda
}

Received: 20 April 2012/Accepted: 3 July 2012/Published online: 28 July 2012

(C) The Institution of Engineers (India) 2012

\begin{abstract}
Bio-fuel is a clean burning fuel made from natural renewable energy resource; it operates in C. I. engine similar to the petroleum diesel. The rising cost of diesel and the danger caused to the environment has led to an intensive and desperate search for alternative fuels. Among them, animal fats like the fish oil have proven to be a promising substitute to diesel. In this experimental study, A computerized 4-stroke, single cylinder, constant speed, direct injection diesel engine was operated on fish oil-biodiesel of different blends. Three different blends of 10,20 , and $30 \%$ by volume were used for this study. Various engine performance, combustion and emission parameters such as Brake Thermal Efficiency, Brake Specific Fuel Consumption, Heat Release Rate, Peak Pressure, Exhaust Gas Temperature, etc. were recorded from the acquired data. The data was recorded with the help of an engine analysis software. The recorded parameters were studied for varying loads and their corresponding graphs have been plotted for comparison purposes. Petroleum Diesel has been used as the reference. From the properties and engine test results it has been established that fish oil biodiesel is a better replacement for diesel without any engine modification.
\end{abstract}

Keywords Performance - Combustion .

Heat release rate - Exhaust gas temperature .

Brake specific fuel consumption - Peak pressure .

Fish oil biodiesel $\cdot$ Brake thermal efficiency

D. K. Ramesha ( $), M I E \cdot$ R. K. Thimmannachar .

R. Simhasan · M. Nagappa · P. M. Gowda

Department of Mechanical Engineering, University

Visvesvaraya College of Engineering, Bangalore University,

Bangalore, India

e-mail: rameshdkuvce@gmail.com

\section{Introduction}

Diesel engine is a popular prime mover for surface transportation, agricultural machinery and industries. More than 6.5 million diesel engines are being used in the Indian agricultural sectors for various activities. Import of petroleum products is a major drain on our foreign exchange sources and with growing demand in future years the situation is likely become even worse. Hence it has become imperative to find suitable fuels, which can be produced in our country $[1,2]$. Biodiesel fuels seem to be providing a promising alternative and solution to all the present problems. Biodiesel can be produced using renewable resources such as vegetable oils (e.g. Soy bean, Canoga, Sunflower, and Palm oil), animal fats (Tallow, Tard, Poultry fat, Fish oils, etc.), or waste cooking oils from the food industry, restaurants or domestic kitchens. Whilst the edible vegetable oils are used for human consumption, usually animal fats are waste from the food processing industries, with a lower cost than vegetable oils, which makes them very attractive as a feedstock for biodiesel production. Thus, the complete recycling of these wastes is a high priority, not only due to the large quantities generated, but also because they represent an economic and environmental problem $[3,4]$. The primary problem associated with straight animal fat oil as a fuel in a diesel engines is caused by high viscosity and low volatility, which causes improper atomization of fuel during injection leading to incomplete combustion and results in formation of deposits on the injectors and cylinder heads, leading to poor performance, higher emissions and reduced engine life [1,2]. The high viscosity of animal oils can be reduced by using transesterification process. The main advantage of this biodiesel is that many of its properties are quite close to that of diesel $[1,2]$. There are numerous other advantages of biodiesel 
Table 1 Properties of diesel, fish oil and FOME

\begin{tabular}{llll}
\hline Properties & Diesel & Fish oil & FOME \\
\hline Density at $15 \mathrm{C}\left(\mathrm{kg} / \mathrm{m}^{3}\right)$ & 850 & 923 & 873 \\
Kinematic viscosity at $40 \mathrm{C}\left(\mathrm{mm}^{2} / \mathrm{s}\right)$ & 2.5 & 29.59 & 6.10 \\
Specific gravity $\left(\mathrm{gm} / \mathrm{cm}^{3}\right)$ & 0.82 & 0.93 & 0.873 \\
Iodine value $(\mathrm{g} / 100 \mathrm{~g} \mathrm{oil})$ & 38.30 & 158 & 85.96 \\
Acid value $(\mathrm{mg} \mathrm{KOH} / \mathrm{g}$ oil) & 0.34 & 2.24 & - \\
Higher heating value $(\mathrm{MJ} / \mathrm{kg})$ & 43 & 39.01 & 41.60 \\
Flash point $(\mathrm{C})$ & 56 & 165 & 110 \\
\hline
\end{tabular}

compared to diesel, including its biodegradability, higher flash point, i.e. less flammability, and it is a clean burning fuel, allowing for $78 \%$ reduction in $\mathrm{CO}_{2}$ lifecycle emissions compared to petroleum diesel [3, 4]. Hence, the potential use of biodiesel fuel using fish oil methyl ester is presented in this paper and Table 1 enlists the various properties of fish oil when compared to Diesel fuel.

\section{Transesterification}

The concept of transesterification process of edible oil with an alcohol (methyl or ethyl) provides a clean burning fuel (Commonly Known as biodiesel) having less viscosity. At industrial level, biodiesel is normally produced by this transesterification process, a chemical process in which triglyceride react with an alcohol(methyl or ethyl) in the presence of an alkali catalyst (usually $\mathrm{NaOH}$ or $\mathrm{KOH}$ in proportions of about $1 \%$ weight of oil) to form fatty acid alkyl mono esters (biodiesel) and glycerol (by-product) $[3,4]$. This occurs in a multiple reaction process including three reversible steps in series, where triglyceride are converted to diglycerides, then diglycerides are converted to monoglycerides, and monoglycerides are converted to esters and glycerol. The fish oil obtained after this transesterification process is usually referred to as fish oil methyl ester [3, 4]. Figure 1 shows the chemical reaction of transesterification of fish oil.

\section{Experimentation}

Whole set of experiments were conducted at the designed injection timing of 24 degrees BTDC, speed of 1500 RPM and 16.5:1 compression ration. The engine was started by hand cranking with diesel fuel supply, and it was allowed to get its steady state (for about 10 minutes). Water to engine cooling jacket was maintained at about $350 \mathrm{lts} / \mathrm{h}$ and water flow pressure to eddy current dynamometer was maintained between 1 to 1.5 bar throughout the experiments, this water flow pressure was maintained by means of $1 / 4$ th HP external water pump. The software was run and operated in

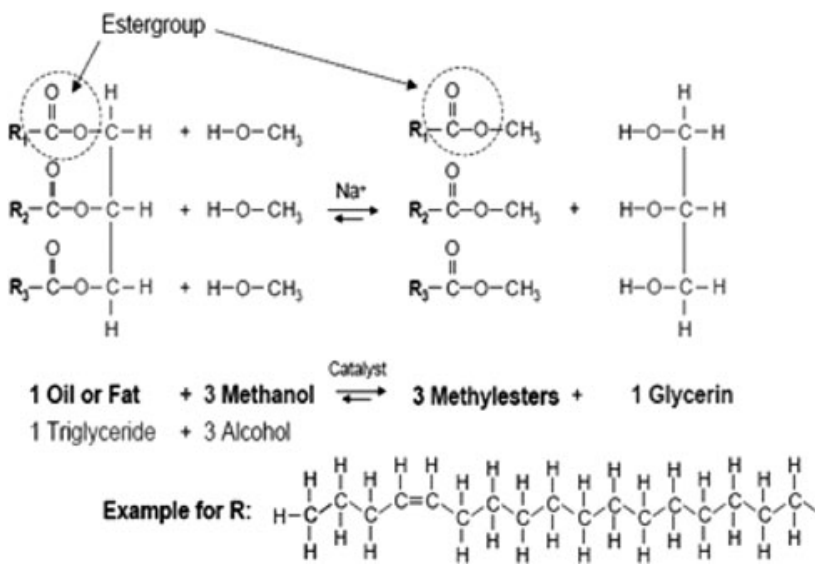

Fig. 1 Transesterifiation of fish oil

online mode with a specific filename. To record the data online, software was logged every time and data was stored in the computer hard disk, which could be retrieved as and when required. Figure 2 shows a schematic representation of the entire experimental set-up. Table 2 provides the engine details. The engine tests were conducted on a computerized single cylinder four-stroke, naturally aspirated, open chamber (direct injection) and water-cooled diesel engine test rig $[1,2]$. It was directly coupled to an eddy current dynamometer that permitted engine motoring either fully or partially. The engine and the dynamometer were interfaced to a control panel, which was connected to a digital computer. The computer software 'Engine Analysis Software' which was supplied by the test rig supplier 'Flow and Force Engineers' was used for recording the test parameters such as fuel flow rate, temperatures, air-flow rate, load etc and for calculating the engine performance characteristics such as brake thermal efficiency, brake specific fuel consumption, heat release rate etc. The experiments were conducted at no-load, $25 \%$ of full load, $50 \%$ of full load, $75 \%$ of full load and full load condition. Data such as fuel flow, air flow, etc were recorded at this condition. The engine was next run with the biodiesel and its blends varying from 10 to 50 and $100 \%$ by volume with Diesel for the same above conditions and performance and combustion tests were carried out as before. However the blends above B30 did't show consistence results when compared with that of Diesel. Hence, the research was confined to the blends up till B30. The data recording was done after the experiment was carried out for three times to obtain a repeatability of values for each blend.

\section{Results and Discussion}

The engine tests were conducted with fish oil methyl ester and its blends for no load to full condition and the 
Fig. 2 Schematic

representation of the test rig. T1, $\mathrm{T} 3$, inlet water temperature; $\mathrm{T} 2$, outlet engine jacket water temperature; $\mathrm{T} 4$, outlet calorimeter water temperature, $\mathrm{T} 5$, exhaust gas temperature before calorimeter; T6, exhaust gas temperature after calorimeter; F1, fuel flow DP (differential pressure) unit; F2, air intake DP unit; PT, pressure transducer; N, RPM decoder; EGA, exhaust gas analyzer (5 gas); SM, smoke meter; Wt, load

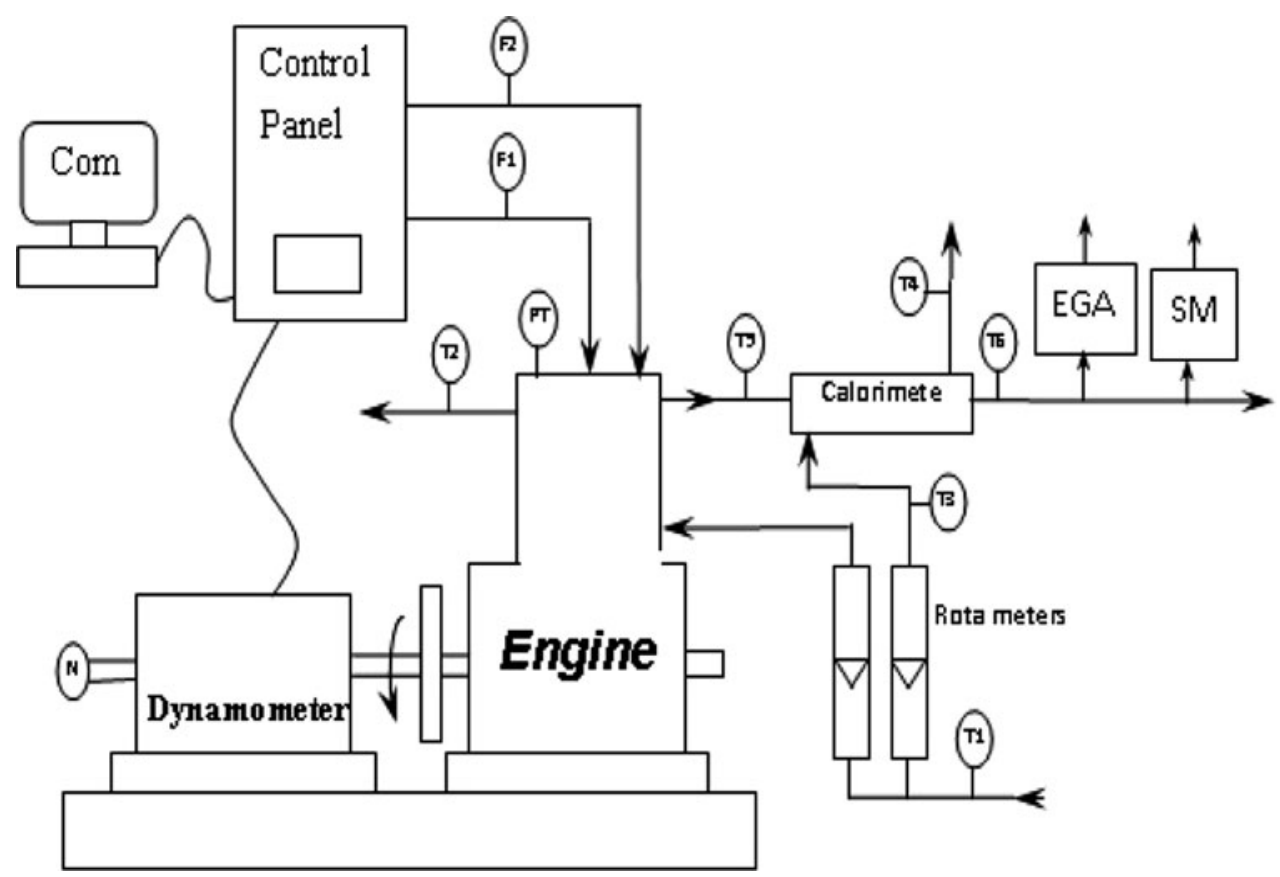

Table 2 Specifications of the engine

\begin{tabular}{ll}
\hline Component & Description \\
\hline Name of the engine & Kirloskar \\
No. of cylinders & 1 \\
Injection system & Direct \\
Capacity & $3.7 \mathrm{~kW}$ \\
Compression ratio & $16.5: 1$ \\
Cylinder bore & $80 \mathrm{~mm}$ \\
Stroke & $110 \mathrm{~mm}$ \\
Cylinder capacity & $553 \mathrm{~cm}{ }^{3}$ \\
Cooling & Water cooled \\
Loading & Eddy current dynamometer \\
Maximum load & $20 \mathrm{~N}-\mathrm{m}$ \\
Rated speed & $1500 \mathrm{rpm}$ \\
Injection pressure & $180 \mathrm{bars}$ \\
\hline
\end{tabular}

corresponding performance and combustion characteristics were studied. For comparison purposes the tests were also conducted with Diesel oil under the same conditions. From the results of these tests it was noticed that the optimum blend for fish oil biodiesel is $20 \%$ by volume.

Performance Analysis

\section{Brake Thermal Efficiency}

The variation of BTE with load for fish oil methyl ester and its blends is shown in Fig. 3. For all fuels, the BTE is

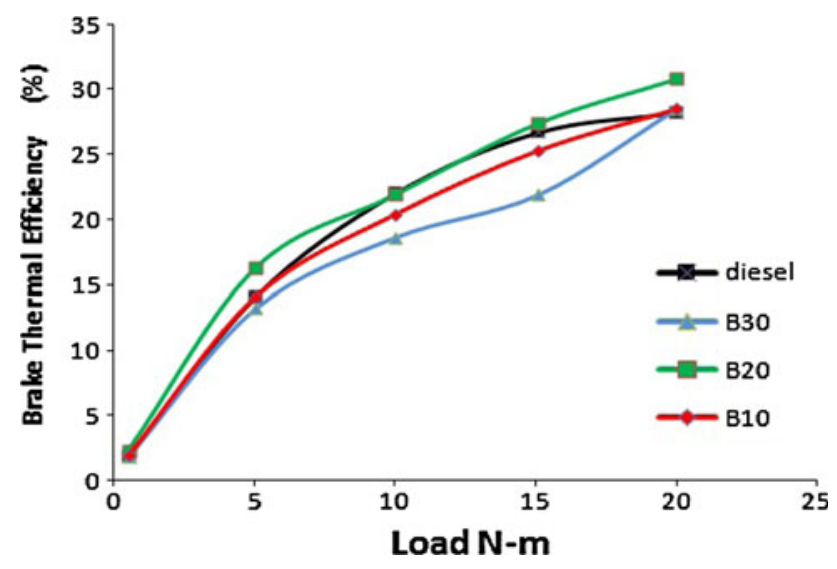

Fig. 3 Variation of BTE with load

improved with increase in load. This was due to reduction in heat loss and increase in power with increase in load $[1,2]$. It is observed that the B20 fuel gave the higher efficiency than the Diesel fuel at full load condition as well as at part load conditions and the efficiency for B10 and B30 fuels are slightly lower than the Diesel but it is seen from Fig. 3 that there was not much significant difference between these fuels at no load condition.

For B20 blend the maximum brake thermal efficiency is obtained as $30.28 \%$ at full load .It is observed that this efficiency is the highest one compared with Diesel (28.2\% at full load), and all the remaining blends of fish oil. This can be attributed to more area coverage of spray formed with B20 blend in the combustion chamber and utilizing the air effectively resulting in more effective combustion [2]. 


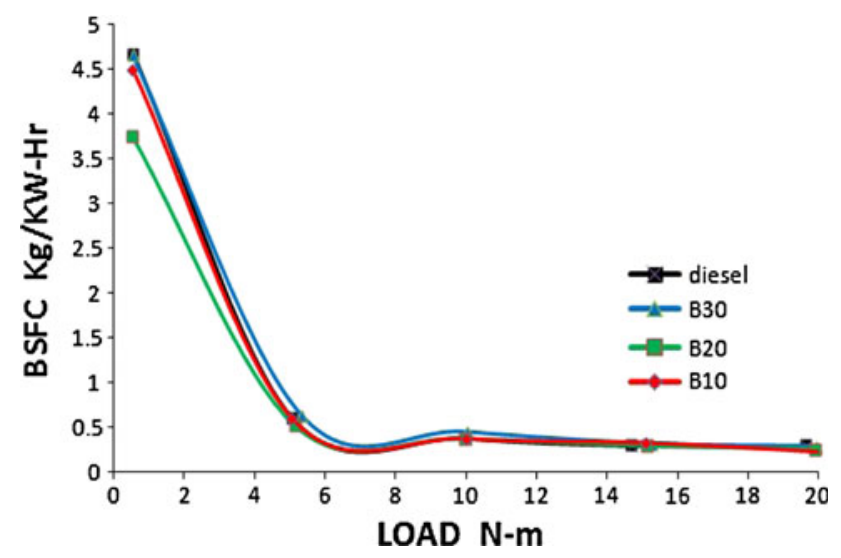

Fig. 4 Variation of BSFC with load

The higher blends generate coarse spray due to increase in viscosity of the blend. This leads to decrease in area of spray formed, resulting in improper combustion [2].

\section{Brake Specific Fuel Consumption}

The variation of BSFC with load of fish oil methyl ester and its blends is shown in Fig 4. All the blends show decreasing trend of BSFC with respect to load. The main reason for this is that the percentage increase in fuel required to operate the engine is less than the percent increase in brake power due to relatively less portion of the heat losses at higher loads $[5,6]$. The figure shows that the BSFC for B10 and B30 fuels is marginally same as that of Diesel fuel, at all loading conditions. Higher the density more will be the discharge of fuel for the same displacement of the plunger of the fuel injection pump [1, 2]. However it is observed that the BSFC for B20 fuel was considerably lower than the Diesel fuel at no load condition. In case of B20 blend the BSFC obtained was minimum and was lower than all other blends and Diesel fuel. This is also due to more area coverage of spray formed

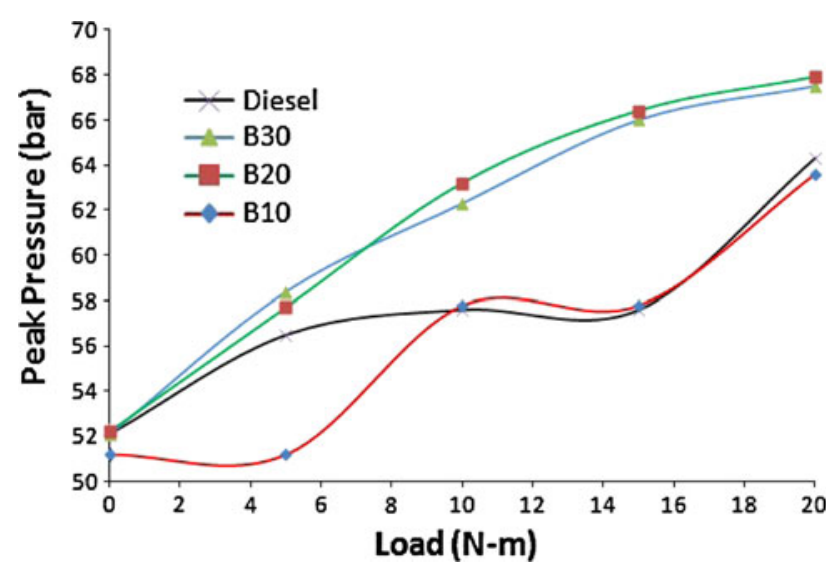

Fig. 5 Variation of peak pressure with load with B20 blend in the combustion chamber and utilizing the air effectively $[1,2]$.

Combustion Analysis

\section{Peak Pressure}

Figure 5 shows the variation of peak pressure of different blends with respect to brake power. From the graph it can be seen that the B20 and B30 blends shows the steady increase in peak pressure with load, whereas the B10 blend shows a significant dip in peak pressure values compared to Diesel. This might be due to increase in viscosity of B10 blend compared to Diesel resulting in improper atomization of the blend inside the engine cylinder $[5,6]$. The maximum pressure was shown by B20 blend at 67.9 bars at maximum load of $20 \mathrm{~N}-\mathrm{m}$. Since the injection pressure and injection timing was kept constant at 180 bars and 24 degrees BTDC respectively, the peak pressure varied directly with the mass of fuel intake. At any given load the fuel intake of B30 blend was more than any other blends. Hence B30 blend showed maximum pressures at 0 and $5 \mathrm{~N}-\mathrm{m}$ loads. However this was not true at part load $(10 \mathrm{~N}-$ $\mathrm{m})$ and maximum load conditions where in B20 blend shows the maximum pressure.

\section{Heat Release Rate}

Figures 6,7 , and 8 show the heat release rates of different blends at no load condition, part load condition and full load condition respectively. From Fig. 6 it is clear that B30 blend shows the maximum heat release of $5,948 \mathrm{~kJ} / \mathrm{s}$ which is greater than that of Diesel by $4.02 \%$. At no load condition the fuel is injected during the delay period, due to this more fuel is injected into the cylinder [7, 8]. As the density of B30 blend is higher more fuel is sucked into the cylinder compared to any other blends at no load, therefore

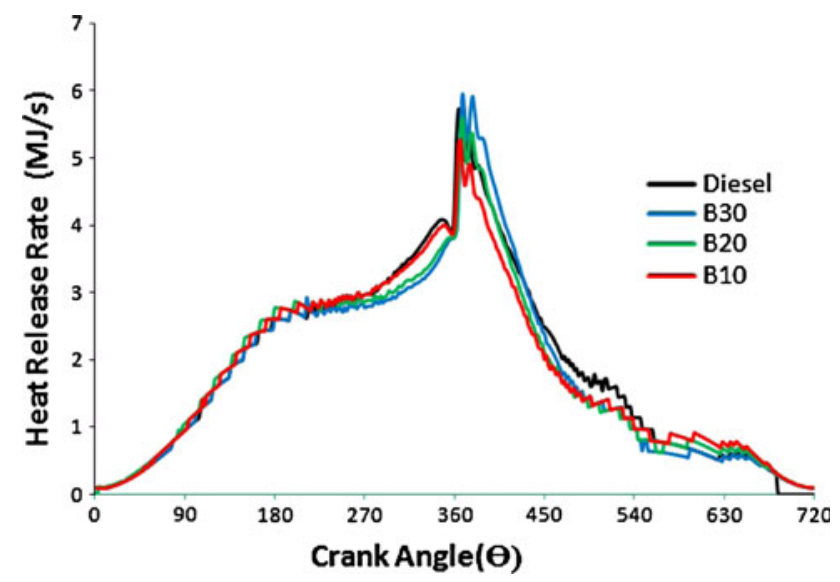

Fig. 6 Variation of HRR with no load (0 N-m) 


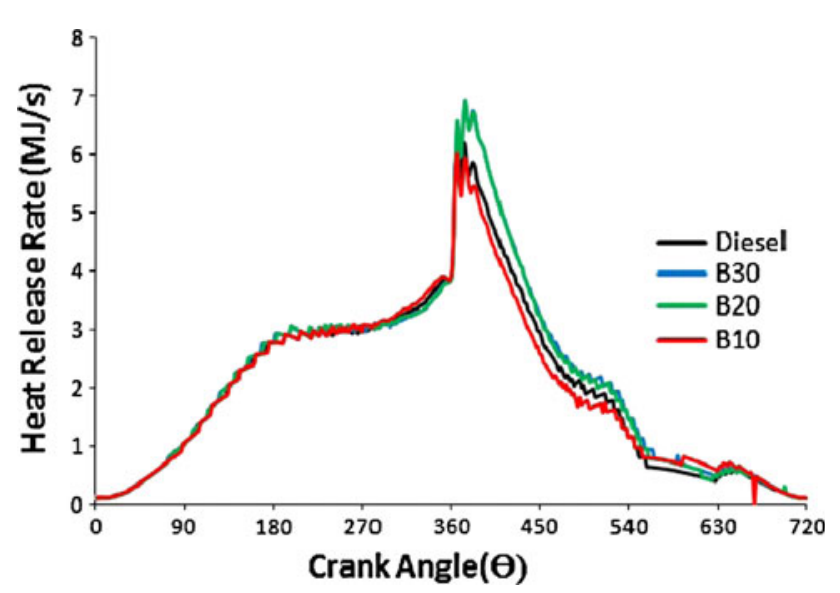

Fig. 7 Variation of HRR with part load (10 N-m)

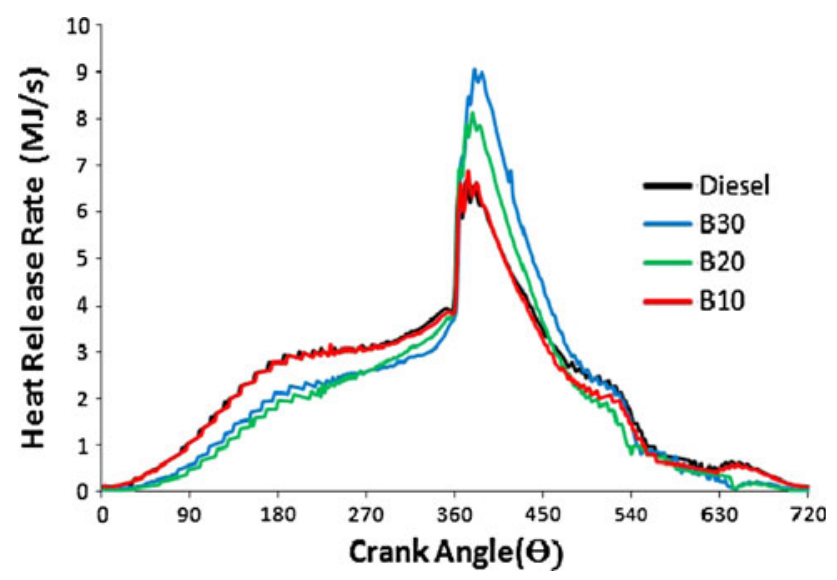

Fig. 8 Variation of HRR with full load $(20 \mathrm{~N}-\mathrm{m})$

it shows the maximum heat release rate [9]. Also from the graph it can be seen that the B10 and B20 blend show lesser heat release rates than Diesel. This was due to decreased calorific values of the two blends [8]. At part load condition the heat loss to the surrounding is high

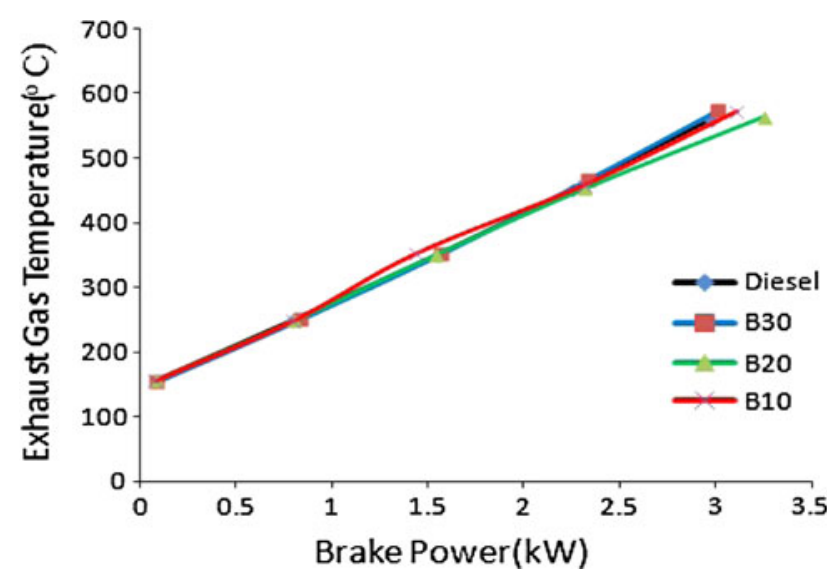

Fig. 9 Variation of EGT with brake power compared to the losses at full load and no load condition $[7,8]$. In this case B20 blend showed a maximum heat release rate of $6921 \mathrm{~kJ} / \mathrm{s}$ (Fig. 7). Form Fig. 8 it can be seen that the B30 blend shows the maximum heat release rate of $9100 \mathrm{~kJ} / \mathrm{s}$ at $20 \mathrm{~N}-\mathrm{m}$ load. At this load the fuel intake is significantly high compared to other loading condition, owing to the fact that B30 blend has more density than any other blends [9]. Hence more uniform combustion is achieved in case of B30 blend [8]. Hence it shows the maximum heat release rate.

\section{Emission Analysis}

\section{Exhaust Gas Temperature}

The variation of EGT (exhaust gas temperature) with load is shown in Fig. 9. It is observed that the EGT is increased with increase in load. It is also observed that there was no much variation in the EGT for blended fuels as compared to Diesel. This could be due to nearly same quantity of fuel being consumed per hour for both diesel and blends. Since heat loss to the exhaust on percentage basis was approximately constant throughout the entire load range, hence same quantity of fuel consumed means same heat was rejected resulting in no much variation in EGT. From Fig. 9, it is found that the EGT is less for B20 fuel compared to all fuels tested. This reveals that effective combustion is taking place during the early part of expansion stroke and the saving in exhaust energy loss is reflected in minimising the energy consumption per unit power output.

\section{Oxides of Nitrogen}

The variation of $\mathrm{NO}_{x}$ (oxides of nitrogen) with load is shown in Fig. 10. The nitrogen oxides results from the oxidation of atmospheric nitrogen at high temperature inside the cylinder of an engine rather than resulting from

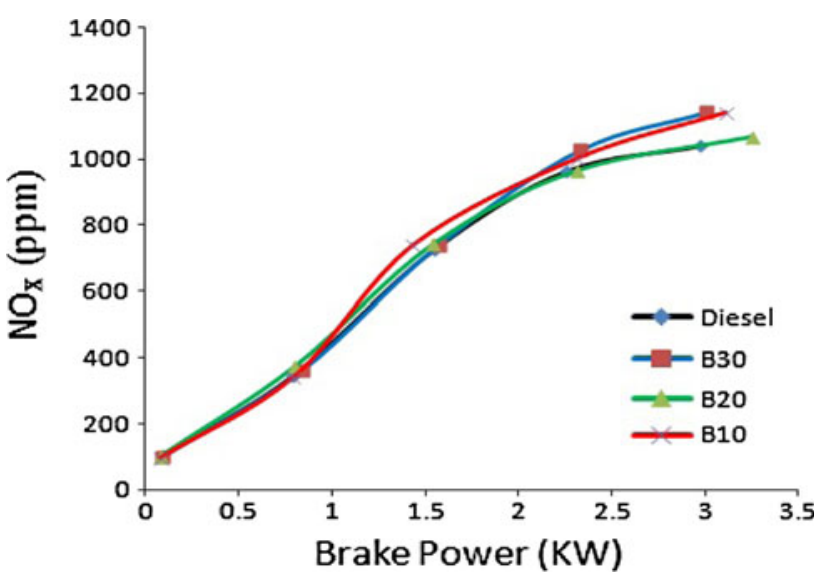

Fig. 10 Variation of $\mathrm{NO}_{x}$ with brake power 
a contaminant present in the fuel. Although nitrogen oxides are considered as major contributor for ozone formation, they are also reality of operating IC engines. It is observed from the Fig. 10 that the amount of $\mathrm{NO}_{x}$ is increased with increase in load for all fuels this is expected because with increasing load the temperature of combustion chamber increases and hence $\mathrm{NO}_{x}$ formation. As it is a strongly temperature dependent phenomenon. However at maximum load, The $\mathrm{NO}_{x}$ emission was increased by $9.9 \%$ in case of B10 and B3O. The $\mathrm{NO}_{x}$ emission was increased by $2.69 \%$ in B20 at the same load. These higher $\mathrm{NO}_{x}$ emissions may be due to higher temperature of the cylinder using biodiesel. The $\mathrm{NO}_{x}$ emission for B20 fuel is measured as $1034 \mathrm{ppm}$, which is lower, compared to diesel.

\section{Unburnt Hydrocarbons}

Figure 11 shows the variation of UBHC (Unburnt Hydrocarbons) with load. The UBHC is increased with increase in load for all fuels. It is observed that the

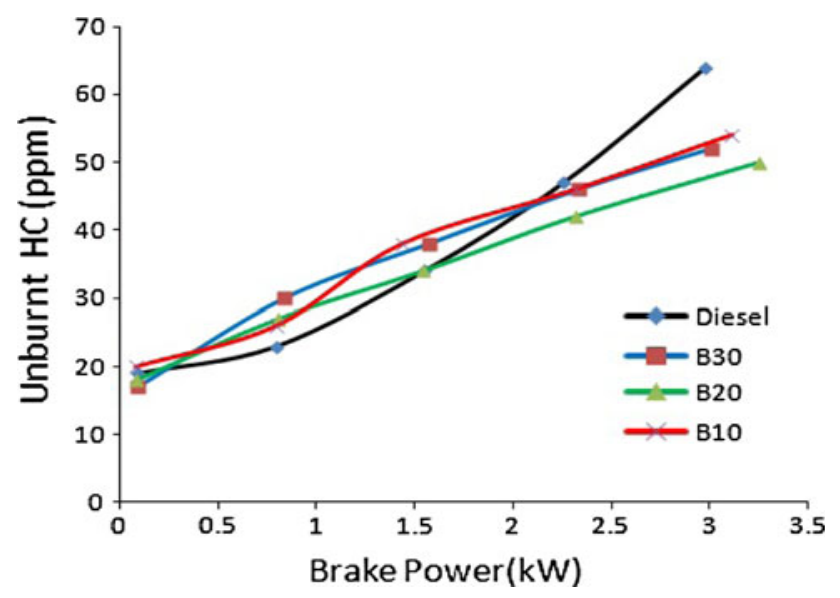

Fig. 11 Variation of UBHC with brake power

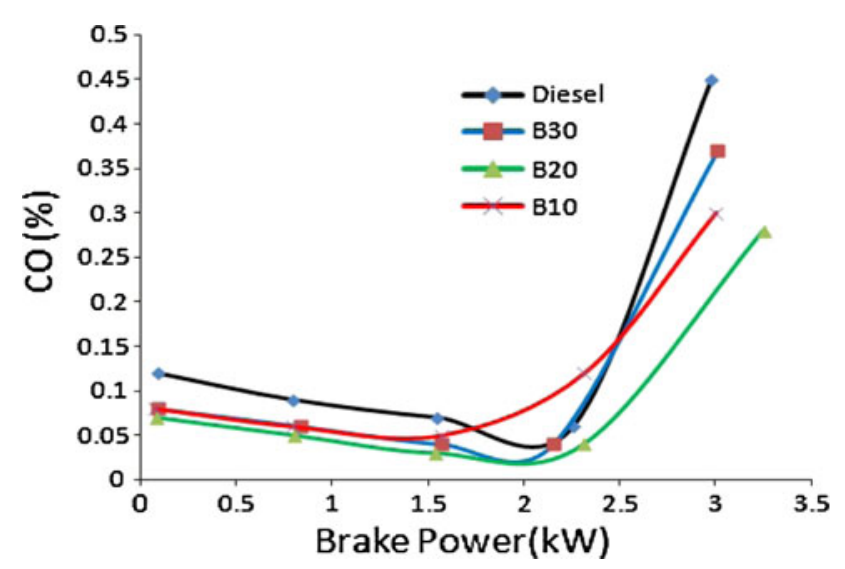

Fig. 12 Variation of $\mathrm{CO}$ with brake power
UBHC emissions for the biodiesel blends are lower than the diesel fuel. The UBHC emission for B20 at full load condition is $21.87 \%$ lesser than diesel. Biodiesel is comprised of animal fat methyl ester, that is they are hydrocarbon chains of original animal fat that have been chemically split off from the naturally occurring triglycerides and its one end of the hydrocarbon chains are oxygenated. The presence of oxygen in the fuel was thought to promote complete combustion that leads to lowering the $\mathrm{HC}$ emissions. These reductions indicate more complete combustion of the fuel.

\section{Carbon Monoxide}

The variation of CO with load is presented in Fig. 12. The $\mathrm{CO}$ is a toxic by-product of all hydrocarbons combustion that is also reduced by increasing the oxygen content of the fuel. More complete oxidation of fuel results in more complete combustion to $\mathrm{CO}_{2}$ rather than leading to the formation of $\mathrm{CO}$. From the figure it is found that the amount of $\mathrm{CO}$ is decreased at part loads and again increased at full load condition for all fuels. It is observed that the $\mathrm{CO}$ emissions for biodiesel blends are lower than the Diesel fuel. It is also observed that the $\mathrm{CO}$ emissions is still lower for B20 fuel at full load condition. The $\mathrm{CO}$ emission for B20 was $37.7 \%$ lower than the diesel fuel. These reductions indicate more complete combustion of the fuel.

\section{Smoke Opacity}

The Fig. 13 indicates the variation of smoke opacity with load. It is found that the opacity is increased with increase in load. The Fig. 13 shows that the opacity is lower for all biodiesel blends compared to diesel fuel. Opacity at full load for B20 is $60.8 \%$, which is lower when compared to $66.3 \%$ of diesel fuel. The lack of heavy petroleum oil

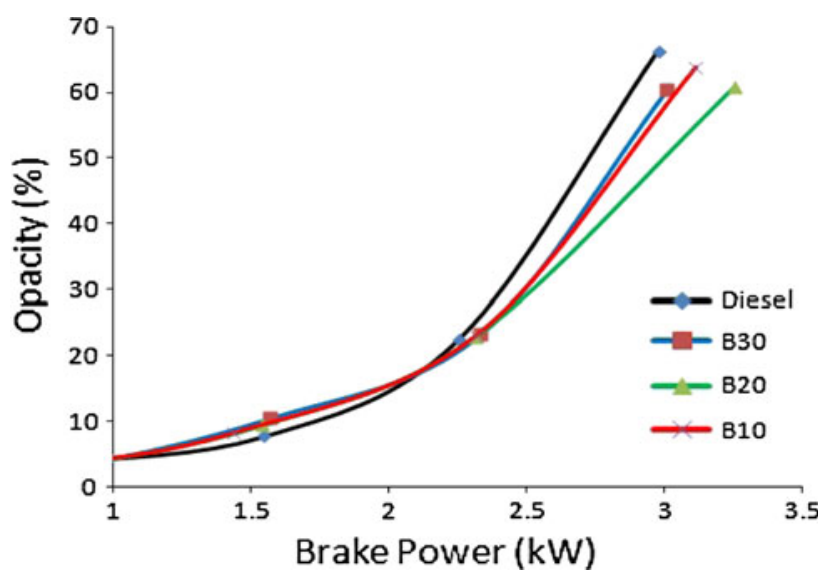

Fig. 13 Variation of smoke opacity with brake power 
residues in the animal fat oil esters that are normally found in diesel fuel is the reason for less smoke. Since the biodiesel contains oxygen, there is an increased efficiency of combustion even for the petroleum fraction of the blend.

\section{Conclusion}

The diesel engine performed satisfactorily on biodiesel, so that the fish oil methyl ester can be used as an alternative fuel in existing diesel engine without any hardware modification. It could be concluded that the blends of fish oil methyl ester with diesel fuel up to $30 \%$ by volume could replace the diesel for running the existing Diesel engine without any hardware modifications and $20 \%$ blend of fish oil methyl esters with diesel fuel was found to be the best blend in regard to performance and combustion compared to all other blends. Also biodiesel reduces the environmental impacts of transportation, reduce the dependence on crude oil imports and offer business possibilities to agricultural enterprises for periods of excess agricultural production. Hence the biodiesel was found to be a potential alternative fuel to Diesel fuel. Since its physical properties are close to those of Diesel fuel and since it is a renewable source of energy it can be right solution to India's oil crisis.

\section{References}

1. P. Srinivasa Rao, K.V. Gopalakrishnan, Use of Non-edible Vegetable Oils as Alternative Fuels in Diesel Engines, DNES Project Report No. 7/2/83 (Indian Institute of Technology, Chennai, 1992), pp. 292-297

2. B.S. Samaga, Vegetable Oil as Alternative fuels for the CI Engine (VIII NCICEC, 1983), pp. B-10-B-12

3. K. Murugu Mohan Kumar, J. Saragan, Critical Review on Biodiesel as Substitute Fuel for Diesel Engines (XVII NCICEC 2001), pp. 181-188

4. A.K. Agarawal, L.M. Das, Biodiesel development and characterization for use as a fuel in compression ignition engines. Trans. ASME 123, 440-447 (2001)

5. O.M.I. Nwafor, Emission characteristics of diesel engine operating on Rapeseed methyl ester. Renew. Energy 29, 119-129 (2004)

6. S. Puhan, G. Sankaranarayanan, Investigation of Mahua Methyl Ester as Renewable Fuel for Diesel Engine (XVIII NCICEC 2003), pp. 589-593

7. S. Kumar, A. Ramesh, B. Nagalingam, Experimental Investigation on a Jatropha oil-Methanol Dual Fuel Engine (SAE 2001-010153, 2001), pp. 1-7

8. K. Pramanik, Properties and use of Jatropha curcas oil and diesel fuel blends in compression ignition engine. Renew. Energy 28, 239-248 (2003)

9. N.V. Bringi, Non-Traditional Oil Seeds and Oils in India (IBH Publishing, New Delhi, India), pp. 143-166 